\title{
Apresentação da Seção Temática Tempo de Escola
}

\author{
Ana Maria Cavaliere'
}

'Universidade Federal do Rio de Janeiro (UFRJ), Rio de Janeiro/RJ - Brasil

Para introduzir o debate sobre o tempo de escola, fio condutor desta seção temática, será preciso, antes de mais nada, situá-lo em termos de suas múltiplas perspectivas de exploração e enfoque. O tema se abre para abordagens teóricas diferentes e, em torno dele, vem se constituindo, no Brasil e no mundo, um grande acervo de investigações e ensaios com múltiplas tendências e sentidos.

Registra-se na produção acadêmica sobre o tempo de escola - entendido aqui como as diversas dimensões da relação entre o tempo e a instituição escolar, seus objetivos, práticas e atores - reflexões que incluem o tempo no interior da escola, o tempo destinado à escola, o tempo referido à escola e muitas outras relações significativas envolvendo os dois termos, inclusive o tempo sem escola ou fora da escola. O que existe de comum nesse conjunto temático é a percepção de que a análise da dimensão tempo - num mundo em que o seu controle estrito, propiciado pela escolarização da vida de crianças e jovens, é a espinha dorsal dos processos formativos que possibilitam o acesso ao conhecimento - se tornou essencial para a compreensão dos problemas, desigualdades e impasses criados ou reproduzidos pelas estruturas educacionais formais vigentes. Sendo assim, o universo de possibilidades abertas nesta seção temática, conforme já constava em sua chamada pública, é bastante amplo e o conjunto de artigos ora apresentados contempla uma parte importante dessas possibilidades.

Pensar sobre o tempo de escola nos faz recuperar o fato, que há muito se tornou evidente, de que a escola, como destino obrigatório e principal da vida das crianças e jovens, não é uma instituição que diz

Educação \& Realidade, Porto Alegre, v. 41, n. 4, p. 975-984, out./dez. 2016. 975 http://dx.doi.org/10.1590/2175-623668297 
Apresentação da Seção Temática - Tempo de Escola

respeito apenas às necessidades de acesso ao conhecimento formal, mas está imbricada com o modelo urbano de vida, a constituição da cidadania e o tipo de organização do trabalho nas sociedades contemporâneas. A questão da duração da jornada escolar - maior ou menor em discussão no Brasil, e em muitos outros países, traz consigo o debate sobre o peso e a ambiguidade do papel da instituição escolar, em parte libertador e em parte legitimador da condição subalterna de grande parte da população, resultante da persistente desigualdade socioeconômica nas sociedades capitalistas modernas. Daí a inevitável pergunta: mais tempo para qual escola? Com isso, são mobilizadas reflexões que envolvem aspectos históricos, sócio-políticos, culturais, pedagógicos e psicopedagógicos.

Como veremos nesta seção temática, os estudos produzidos estão muitas vezes diretamente referidos a políticas públicas implementadas que modificam o tempo escolar e sua organização e geram dúvidas, polêmicas e necessidade de avaliação. Outras vezes, seguem os caminhos da reflexão sobre o tempo, baseada na análise de situações singulares, seja de indivíduos, salas de aula ou agrupamentos específicos de alunos ou professores.

No Brasil, um incremento significativo do tema no cenário acadêmico se deu nos últimos anos da primeira década deste século, e se explica pelo surgimento, em âmbito federal estadual e municipal, de programas de ampliação da jornada escolar nas redes públicas de ensino.

Essas políticas de ampliação do tempo de escola se apresentam, quase sempre, acompanhadas de propostas que, se por um lado pretendem fortalecer o papel social e cultural da escola numa realidade em que ela, historicamente, se caracteriza por sua condição minimalista - em relação não apenas ao tempo, mas a toda a sua estrutura - por outro, questionam suas funções e tarefas e, em alguns casos, sua hegemonia como instituição responsável pela difusão do saber e formação da cidadania, vista como excludente e empobrecedora. Assim, em associação com a proposta de ampliação do tempo que os alunos ficam sob a responsabilidade da escola, são desenvolvidos e difundidos conceitos como os de educação integral, educação integrada, comunidades educativas, cidades educadoras e outros que, de modo geral, associam novas responsabilidades, atividades, agentes e espaços à vida escolar e novas relações desta com a localidade e outras instituições sociais.

Ainda sobre as produções acadêmicas que contemplam a questão da jornada escolar no Brasil, destacamos o levantamento realizado por Rosa (2016) no Banco de Dados da Capes, entre os anos 2000 e 2012, que encontrou 27 teses e 152 dissertações a partir dos descritores tempo integral, horário integral, educação integral e programa Mais Educação. A presença do descritor programa Mais Educação no levantamento é resultado do alcance nacional desse programa, criado em 2007 para induzir a ampliação da jornada escolar. Estruturado em um formato que envolveu parcerias com organizações sociais e atividades fora da 
escola, trouxe um novo impulso aos estudos sobre o assunto. Dentre os 11 artigos deste dossiê, cinco deles fazem referências ou analisam o Programa Mais Educação. Entretanto, quando da redação desta introdução, em setembro de 2016, o programa se encontrava interrompido e a maioria das escolas que a ele aderiram já não recebiam os incentivos materiais e pedagógicos previstos.

Além dos programas governamentais, outro aspecto a explicar o crescimento do interesse pelo tema é a sua presença - na forma de incentivo e regulamentação da escola de tempo integral - em documentos recentes importantes da educação brasileira, tais como a LDBEN-1996, o PDE-2007 e o PNE-2014. Entretanto, a bandeira da escola de tempo integral é apenas um ponto de partida (e sempre controverso). Como já indagamos, mais tempo de escola para quê? Para quem? Com quais profissionais? Em quais espaços? Com que tipo de relação com o tempo não escolar? A referida bandeira tem dado oportunidade a uma expansão das reflexões sobre a organização do tempo escolar, que vai muito além dela mesma, e contribui com o aprofundamento do pensamento sobre as lógicas naturalizadas do cotidiano escolar e sua relação com a manutenção das desigualdades e com o direito à educação e ao conhecimento.

Os artigos deste dossiê mostram que a análise do tempo de escola no Brasil e no mundo não se esgota sem os profundos e necessários debates sobre as temporalidades vividas, as formas impeditivas ou propiciadoras da apropriação autônoma do tempo nos processos formativos de alunos e professores, o entrelaçamento entre tempo e espaço escolar, entre outros. Evidenciam, também, a circulação internacional de políticas e debates. A agenda da Unesco na América Latina recomendou a ampliação da jornada escolar nos anos 2000 e Chile, Uruguai, Venezuela e Argentina também implementaram programas de escolas de tempo integral (Fanfani, 2010) como estratégia para a melhoria da equidade e da qualidade educacional. Com a presença do texto de Soledad Vercellino temos uma representação desse processo na Argentina.

Já na bibliografia europeia a discussão sobre o tempo de escola acompanha as indagações, cada vez mais frequentes, sobre as fronteiras da escola (Rayou, 2015). Observa-se a pouca definição dos limites entre o tempo escolar e o tempo não escolar, seja devido ao processo de escolarização da vida (ou à sua antítese, a desescolarização da escola), ou devido ao processo de multiplicação dos canais de divulgação do conhecimento, bem como das formas de sua utilização, ao mesmo tempo fragmentada, difusa e coletiva. A discussão está associada também aos programas europeus de educação prioritária e outras iniciativas que buscam enfrentar o crescimento da desigualdade educacional nos países desenvolvidos e aparece aqui representada pelo texto das autoras francesas Audrey Boulin e Michèle Guigue.

A seguir, apresentaremos cada um dos trabalhos desta seção temática de modo a orientar o leitor em um mergulho qualificado e atu- 
alizado no tema. Nesta apresentação, os textos estão organizados de acordo com suas similaridades, formando pequenos subconjuntos que, entretanto, dialogam entre si e se complementam.

\section{Aspectos Institucionais e Organizacionais}

Uma das variantes dos estudos sobre o tempo de escola, em contextos de sua ampliação, é a análise dos formatos organizacionais da vida escolar - usos tradicionais e inovadores do tempo, relações trabalho/lazer, hierarquias espaço-temporais. Nesses estudos o tema se insere teoricamente na sociologia das organizações escolares e na compreensão da escola com instituição complexa. O texto L'Internat Scolaire, Limites et Paradoxes d'une "Institution Totale" de Michèle Guigue e Audrey Boulin mostra o internato como uma tentativa de fechar as fronteiras da escola para torná-la mais segura e eficaz. Associando o internato a uma instituição total, nos moldes descritos por Erving Goffman, o estudo focaliza uma nova versão de internatos públicos que surge recentemente na França. A investigação empírica, realizada em duas escolas deste tipo, entre os anos de 2010 e 2015 mostra que a escolha dessas escolas pelas famílias se explica pela preocupação com os problemas da vida dos bairros e pela expectativa de uma experiência escolar mais eficaz. Nessas instituições pretende-se a utilização rígida e intensiva do tempo e as atividades que seriam de lazer são escolarizadas, turvando-se a fronteira entre trabalho e diversão. Entretanto, os problemas enfrentados no cotidiano aproximam e personalizam as relações humanas, criando situações que ultrapassam aquelas tipicamente escolares, alcançando esferas da afetividade que geram arranjos, acordos tácitos e negociações frente às dificuldades e transgressões. Nos internatos, apesar de se oferecer mais escola, a intensa vida coletiva que eles proporcionam termina por, paradoxalmente, fragilizar a ordem escolar. Tal como descrito no estudo, o internato põe em questão as competências sociais que se espera da escola, desestabilizando, muitas vezes, seu quadro normativo e as estratégias dos profissionais, gerando novas formas de relação institucional o que leva as autoras a se perguntarem se não seria este um resultado da dinâmica democrática do mundo hoje.

Em seguida, o trabalho da pesquisadora argentina Soledad Vercellino, Ampliación del Tiempo y Dispositivo Escolar: oportunidades y resistencias, investiga a relação entre extensão da jornada e mudanças mais profundas na instituição escolar. Apresenta pesquisa realizada em duas escolas primárias, da província argentina de Rio Negro, que integram um programa de ampliação da jornada escolar. Entendendo o tempo como um elemento duro do dispositivo escolar, no sentido foucaultiano do termo, o estudo mostra a força desse dispositivo frente às inovações que a jornada ampliada trouxe no caso das escolas estudadas. Nelas, as oficinas que integram esse tempo ampliado introduzem questionamentos na gramática institucional e deixam muitas dúvidas

978 Educação \& Realidade, Porto Alegre, v. 41, n. 4, p. 975-984, out./dez. 2016. 
e perguntas no ar, conforme mostrou o material empírico da pesquisa. A forma de organização do tempo termina por interferir em diversos outros componentes do escolar e questiona uma ordem institucional conservadora que se encontra em desacordo com mudanças ocorridas na sociedade. O estudo da ampliação do tempo permitiu o desvelamento do dispositivo escolar, com seu caráter de rede construída ao longo da história, e sua resistência às novas possibilidades que, entretanto, emergem com força e, segundo a autora, devem, com a participação inclusive da universidade, ser valorizadas e analisadas visando às mudanças necessárias.

\section{Os Alunos e as Práticas em Sala de Aula}

Os estudos sobre o tempo de escola, para além das questões da duração da jornada, constituem um caminho já consolidado que vem sendo realizado nas áreas da psicologia educacional, da didática e do currículo. A distribuição de tempos e espaços define e expressa prioridades, atitudes, metodologias e metas. Essa distribuição envolve as condições subjetivas dos atores e também as condições objetivas dos equipamentos e recursos escolares. Analisar o estabelecimento e uso do tempo na organização do trabalho pedagógico das instituições de ensino requer, para que se obtenha resultados significativos, uma compreensão da ação pedagógica como prática social, isto é, como prática que se insere nos principais processos pelos quais funciona a sociedade.

Nessa direção, os artigos Infância e Escola: tempos e espaços de crianças, de Anabela Kohlmann Ferrarini, Fabiana Oliveira Queiroz e Raquel Gonçalves Salgado e Aspectos Temporais na Aula: cadência, ritmo e momento oportuno de Flávia Anastacio Paula focalizam, no interior da instituição escolar, a vivência dos alunos e professores e as dinâmicas da sala de aula em suas injunções e superações temporais.

No primeiro, observam-se as formas infantis de transcender a organização tempo-espacial estabelecida. Olhar a criança como fonte de aprendizado sobre o tempo e sua complexidade é a proposta do texto, na perspectiva de que a criança é um sujeito com saberes legítimos e não somente um objeto a ser conhecido. A partir de uma reflexão sobre o tempo em dois estudos realizados numa mesma escola pública do município de Rondonópolis (MT), com crianças das séries iniciais do ensino fundamental, as autoras procuram mostrar o quanto o contexto escolar expressa a relação impositiva dos adultos e da sociedade em relação aos tempos do sujeito que, muitas vezes, apesar disso, transcende ao que está posto e se liberta para outros tempos. Realizando um diálogo criativo com a poesia de Mario Quintana, buscam captar a singularidade da infância em sua forma de romper com a linearidade do tempo cronológico. Além de entrevistas e questionários com professores e mães, as pesquisadoras trabalharam com as crianças a confecção de mapas vivenciais, procedimento que conjuga recursos visuais e narra-

Educação \& Realidade, Porto Alegre, v. 41, n. 4, p. 975-984, out./dez. 2016. 979 
tivas, visando conhecer suas vivências no contexto escolar, bem como compreender os seus modos de ser, pensar, estar e agir neste espaço/ tempo.

O artigo de Flavia Anastacio Paula teoriza sobre as formas de uso do tempo numa sala de aula. Tendo como fio condutor o ajuste entre Chronos e Kairós, focaliza o uso dos tempos na prática das aulas de uma turma de alfabetização destacando sua relação com o ensino. A autora desenvolveu o estudo em uma escola que contém os ingredientes escolares de organização temporal típicos e uniformes. Fundamentando-se em autores como Michel Certeau e Agnes Heller, acompanha uma professora alfabetizadora experiente em uma turma de crianças de seis anos. A professora foge ao comum, exerce seu trabalho com autonomia e afirma que sua maior angustia é a preservação de sua possibilidade de decidir, sem submeter-se a um modelo exterior de uso do tempo no cotidiano do processo de alfabetização. A tensão entre a prescrição de um tempo linear e a realidade de um tempo sempre atravessado se revela nas observações do caderno de campo da pesquisadora. As prioridades, definidas pela professora, materializam-se em rotinas, usos diferentes do espaço da sala de aula, frequências, continuidades e horários privilegiados, exercendo uma ética do trabalho regulado pela tarefa e não simplesmente pelo relógio. A autonomia de seu trabalho é mantida em função da clareza que revela quanto aos seus objetivos. O tipo de organização do tempo proposto pela professora é assimilado e incorporado pelos alunos. A simultaneidade e a sincronia de atividades paralelas são regidas pela professora, visando sempre o ensino, destacando-se que as oportunidades criativas surgem, muitas vezes, em momentos de dispersão, isto é, em momentos kairológicos.

\section{Conhecimento Escolar, Proteção Social e Sentido da Escola}

Voltando à abordagem da ampliação do tempo de escola, dois artigos a relacionam à questão do conhecimento na escola. $\mathrm{O}$ primeiro, Relação com o Saber na Escola em Tempo Integral de Maria Celeste Fernandes Souza e Bernard Charlot pergunta pelo sentido da escola e de sua ampliação na vida dos indivíduos. Evidencia e trabalha os binômios proteção/educação e ampliação do tempo/aprendizagem. Tendo como cenário a universalização do tempo integral no município de Governador Valadares (MG), nos anos finais do ensino fundamental, com a participação do Programa Mais Educação, procura compreender o fenômeno constatado da diminuição do número de alunos nesse segmento. Ao abordar a relação com o saber, na escola em tempo integral, o texto mostra as diferentes formas pelas quais os alunos - a depender de suas já estabelecidas relações com a escola - sentem e interpretam a ampliação da jornada. Os não integrados à escola, que a frequentam sem uma efetiva adesão, recebem a ampliação da jornada como castigo ou mesmo tortura, mantendo-se nela apenas por solidariedade ou obe-

980 Educação \& Realidade, Porto Alegre, v. 41, n. 4, p. 975-984, out./dez. 2016. 
diência à família. Os que encontram dificuldades na escola, mas lutam para superá-las percebem o horário ampliado como oportunidade de aprenderem mais, a partir de um contato mais intenso e prolongado com os professores. Quanto aos estudantes que não encontram dificuldades de aprendizagem, embora reconheçam que o tempo integral os aproxima dos professores, também sentem que ele pode ser um empecilho às suas iniciativas próprias de aprender mais fora da escola. O estudo mostra que, especialmente para os jovens, não é possível ampliar a jornada escolar sem que isso represente um fortalecimento do sentido da escola, com efeitos de maior mobilização dos alunos para aprender e estar dentro dela.

O artigo seguinte, Sobre Tempo e Conhecimentos Praticados na Escola de Tempo Integral, de Lígia Martha Coelho e Lucia Velloso Maurício, entende o conhecimento como a natureza primeira da existência da escola e desenvolve o questionamento sobre de que maneira a ampliação da jornada escolar pode favorecer a criação de caminhos para que a aquisição dos conhecimentos se efetive em meio a projetos de sociedade em disputa e tendo em vista a possibilidade da emancipação. Dialogando com autores como Bernard Lahire e Pierre Bourdieu as autoras dão relevo ao trabalho pedagógico com língua escrita, linguagens e comunicação - recuperando experiências anteriores de ampliação da jornada escolar no Brasil - como possível chave articuladora para essa ampliação. Debruçam-se ainda sobre uma interpretação da condição atual da educação brasileira, com base em autores como Eveline Algebaile e José Carlos Libâneo, na qual se constataria uma ampliação para menos - inclusive do tempo - que levaria a uma escola do acolhimento social em detrimento da escola do conhecimento. O texto critica certos aspectos do Programa Mais Educação e alerta para a possibilidade de que a ampliação da jornada escolar no Brasil venha a se fazer com base na primeira configuração, sem superar a exclusão, e sugere um forte compromisso com os conhecimentos universais historicamente construídos.

\section{Qualidade e Desempenho}

A instabilidade das políticas públicas, bem expressa na interrupção do Programa Mais Educação já aludida neste texto, assim como a ausência de avaliações, que impedem a aferição dos impactos das políticas e programas, são aspectos para os quais chama a atenção o texto Tempo de Escola e Gestão Democrática: o programa Mais Educação e o IDEB em busca da qualidade da educação, de Elisangela da Silva Bernado e Ana Carolina Christovão. Em sua parte mais consistente, o trabalho mostra um estudo exploratório que combinou levantamento de dados educacionais e realização de entrevistas com gestores escolares em escolas contempladas com o Programa Mais Educação (PME) da rede municipal de ensino do Rio de Janeiro (RJ). Após analisar os indicadores gestão democrática e regime de atendimento nessa rede escolar, nos anos 
de 2013 e 2014, cotejando-os as escolas com o PME, as autoras concluem não ser possível estabelecer uma relação causal entre eles. Da mesma forma, em relação à evolução do Ideb entre os anos de 2005 e 2013, o estudo não encontrou indícios positivos quanto à melhoria dos indicadores de desempenho das escolas nas quais foi implantado o PME. Relação esta que, de todo modo, seria difícil de estabelecer visto que o PME não se destina ao conjunto de alunos de uma escola, mas a uma parcela, quase sempre minoritária, deles.

\section{Micropolítica Cotidiana e Construção Coletiva da Docência e do Currículo}

Em uma escola minimalista, os processos democráticos de construção coletiva de soluções para o avanço da qualidade educacional são liminarmente barrados pela falta de tempo: não há tempo físico, nem tempo psicológico, para o encontro, a troca, a criação, entre alunos, professores e demais profissionais (que, aliás, quase não existem) no interior da escola. Os artigos O Tempo no Mundo Contemporâneo: o tempo escolar e a justiça curricular de Branca Jurema Ponce e Formação Continuada em Escolas de Tempo Integral: narrativas de professoras de Inês de Souza Bragança e Juliana Godói de Miranda Perez investigam os processos coletivos no interior da escola e avançam na valorização desta questão. No primeiro, a educação escolar, e particularmente os currículos, são apresentados como espaços de disputa de poder. Entre as políticas que expressam essa disputa, destacam-se as que incorporam um uso corrido e desgastante do tempo, alinhado com um ideário empresarial que o coloca a serviço da acumulação de capital. Assim, segundo a autora, pensar e repropor o tempo escolar na busca pela justiça curricular se tornou um desafio. Como fazer um tempo de construção formativo em um mundo em que, freneticamente, vive-se o tempo esvaziado de significados? Trabalhando essa ideia, propõe e analisa elementos que propiciariam a compreensão da temporalidade vivida, entre outros: finalidade, relatividade-permanência, liberdade. A partir deles sugere a efetivação de um caminho que suponha um tempo escolar construtivo em direção à justiça curricular.

No artigo que se segue, de Inês de Souza Bragança e Juliana Godói de Miranda Perez, a formação continuada de professores é o foco, e o trabalho a analisa no contexto de escolas situadas em três municípios do estado do Rio de Janeiro. O estudo fundamenta-se num campo teórico que entende a formação humana em suas múltiplas dimensões - políticas, epistemológicas e existenciais - observando o entrelaçamento entre experiências, memórias e narrativas. Passando por autores como Andy Hargreaves, Walter Benjamin e Jorge Larrosa discute a noção de espaçotempo na formação docente. Apresenta um levantamento das políticas públicas brasileiras recentes dirigidas à formação docente que se realiza no cotidiano das escolas, e reporta a narrativa de três professo-

982 Educação \& Realidade, Porto Alegre, v. 41, n. 4, p. 975-984, out./dez. 2016. 
ras atuantes em escolas de tempo integral. A partir da palavra dada e da escuta, de acordo com a concepção de pesquisa narrativa (auto)biográfica, observa a criação de novos espaçostempos de formação produzidos pelas professoras. Elas relatam, como acontecimento biográfico significativo, a vivência na escola de tempo integral com aquilo que ela propicia de aprofundamento das relações com o currículo, o conhecimento e os colegas, modificando a micropolítica cotidiana e o processo de formação docente continuada.

\section{Repensando as Fronteiras Institucionais}

A questão do tempo escolar tem funcionado como um disparador de debates e propostas de mudança na própria concepção de escola, nos seus modos de existência, na sua característica de organização fechada e autossuficiente, inquirindo sobre o seu sentido e alcance. Pensar o tempo de escola é pensar as fronteiras da escola, as imprecisões de seus limites, do ponto de vista institucional, de seus atores e objetivos. Os dois artigos a seguir apresentados, tratam da relação da escola com o que está fora dela. Pensam a existência de práticas e comunidades educativas que ultrapassam os tempos e espaços escolares e a necessidade de se repensar as interações da instituição escolar com essas outras instâncias de vida e formação. Em Tempo de Escola ou Tempo de Aprender? lições de José Luiz, William Rodrigues Barbosa indaga a possibilidade de delimitação do tempo para a escola na vida dos cidadãos. Essa pergunta carrega outra consigo, sobre a escola como lócus privilegiado da construção dos saberes e do sujeito cognoscente e ainda outra decorrente, sobre o papel de outros tempos-espaços e interações sociais nessa construção. Recupera a história de vida de um homem que não chegou a frequentar a escola de educação básica formal, mas, ainda assim, constituiu-se sujeito leitor e escritor de textos próprios. Procura desvendar como se entrelaçaram as práticas sociais e escolares em José Luiz, sujeito octogenário, excluído do direito à escola, que o autor toma como informante e parceiro de sua investigação. Tendo por base o conceito de educação ao longo da vida pergunta-se como o desejo de aprender foi constituído, no caso, fora do espaço escolar formal. Pergunta-se como as aprendizagens transpuseram os muros da escola e trabalha a concepção de tessitura de conhecimento em rede. Conclui que é impossível desconsiderar a importância do tempo de escola na infância para a formação dos indivíduos, lacuna que ele percebe em seu interlocutor, mas ressalta a necessidade de reconhecimento e promoção de outros tempos de aprendizagem em todas as fases da vida.

Em seguida, o artigo de Lúcia Helena Alvarez Leite e Paulo Felipe Lopes de Carvalho, Educação (de Tempo) Integral e a Constituição de Territórios Educativos vincula a questão da ampliação da jornada escolar à concepção de educação integral na busca de um tipo de formação de crianças e jovens que possa alcançar a cultura, a relação com 
a comunidade e com a família e o diálogo com o território. Apresenta pesquisa realizada na Rede Municipal de Educação de Belo Horizonte (MG), sobre o Programa de Educação Integral (PEI), que amplia a jornada escolar para 9 horas diárias utilizando-se de oficinas desenvolvidas no horário oposto ao das aulas regulares, em diversos espaços sociais e institucionais como ONGs, associações, parques, clubes, igrejas e universidades. O estudo destaca a proposta do programa de estruturação de um território educativo, bem como da sintonia das ações educativas com os contextos sociais e as dinâmicas do bairro onde se situa a escola. Destaca ainda o papel dos oficineiros cujo diferencial estaria no fato de que, devido à proximidade de suas vivências, enxergam os educandos para além da função de alunos, como sujeitos com direitos, vida, percursos, corpos, tramas. A investigação se deu em uma das escolas que integram o programa e compreendeu além de entrevistas com educadores, o acompanhamento contínuo, em 2013 e 2014, de cinco adolescentes participantes os quais confeccionaram mapas mentais, método que pretende captar a expressão do sensível e do vivido por meio de desenhos. Conclui que o programa estudado suscita a produção de um espaço geográfico educativo particular, fluido e maleável, a partir de uma dinâmica que valoriza os espaços de vivência.

Enfim, o conteúdo deste dossiê nos mostrou que a maior contribuição do recorte tempo de escola, como conjunto temático, é o que ele proporciona em termos de novos olhares sobre aspectos da educação escolar os quais muitas vezes encontram-se cristalizados em discussões assentadas em áreas disciplinares específicas. Sua característica necessariamente interdisciplinar pode provocar, instigar e desestabilizar visões. Que as possibilidades contidas neste dossiê floresçam e contribuam cada vez mais com a construção de um modelo de escola que possa garantir os direitos ao conhecimento e à cidadania.

\section{Referências}

FANFANI, Emilio Tenti (Coord.). Estado del Arte: escolaridad primaria y jornada escolar en el contexto internacional. Estudio de casos en europa y america latina. Buenos Aires: Instituto Internacional de Planeamiento de la Educación/ UNESCO, 2010.

RAYOU, Patrick (Coord.). Aux Frontières de l'École: institutions, acteurs et objets. Paris: Presses Universitaires Vincennes (PUV), Culture et Société, 2015.

ROSA, Alessandra Victor Nascimento. Pesquisando a Relação Educação Integral e(m) Tempo Integral e Currículo no Brasil - período 2000-2012. O que revelam as pesquisas de mestrado e doutorado? 2016. Tese (Doutorado em Educação) - Pontifícia Universidade Católica, Rio de Janeiro, 2016.

Ana Maria Cavaliere é professora da Faculdade de Educação e do Programa de Pós-Graduação em Educação da Universidade Federal do Rio de Janeiro. E-mail: anacavaliere@uol.com.br 